\title{
Thoracoabdominal aortic aneurysm repair with patent gastroepiploic artery graft
}

\author{
Toshihiro Fukui, MD, Muneaki Yamada, MD, Minoru Tabata, MD, MPH, and \\ Shuichiro Takanashi, MD, Tokyo, Japan
}

\begin{abstract}
The gastroepiploic artery (GEA) has been used as a graft for coronary artery revascularization with favorable outcomes. ${ }^{1}$ This artery has the advantage of being suitable for an in situ graft to the right coronary artery. Herein, we report a case of thoracoabdominal aortic aneurysm (TAAA) repair in a patient who had previously undergone a GEA graft for coronary artery revascularization.
\end{abstract}

\section{CLINICAL SUMMARY}

A 67-year-old man had undergone coronary artery bypass grafting (CABG) at another hospital 7 years earlier. The left internal thoracic artery had been anastomosed to the left anterior descending artery. The GEA and the radial artery had been used to revascularize the right and left circumflex coronary arteries and a diagonal branch as a composite Y-graft. His postoperative course had been uneventful. He was referred to our hospital because of a TAAA. Computed tomography demonstrated an aneurysm extending from above the celiac artery to the common iliac arteries bilaterally. We planned repair of the TAAA using partial cardiopulmonary bypass $(\mathrm{CPB})$. Coronary angiography performed 6 weeks before the operation confirmed the patency of all bypass grafts.

A double-lumen endotracheal tube was used for anesthesia. The left femoral artery and vein were exposed for CPB. The descending thoracic aorta, abdominal aorta, and bilateral iliac arteries were completely exposed through a left thoracoabdominal incision. The proximal aortic clamp was placed in the thoracic cavity, followed by the distal aortic clamp approximately $3 \mathrm{~cm}$ distal to the proximal aortic clamp. After aortic clamping, partial CPB was started to preserve the visceral organs, especially the heart and thoracolumbar spinal cord. The aorta was divided between the

\footnotetext{
From the Department of Cardiovascular Surgery, Sakakibara Heart Institute, Tokyo, Japan.

Disclosures: Authors have nothing to disclose with regard to commercial support. Received for publication April 21, 2011; revisions received May 20, 2011; accepted for publication June 27, 2011; available ahead of print July 22, 2011.

Address for reprints: Toshihiro Fukui, MD, Department of Cardiovascular Surgery, Sakakibara Heart Institute, 3-16-1 Asahi-cho, Fuchu, Tokyo 183-0003, Japan (E-mail: tfukui-cvs@umin.ac.jp).

J Thorac Cardiovasc Surg 2012;143:236-7

0022-5223/\$36.00

Copyright (c) 2012 by The American Association for Thoracic Surgery doi: $10.1016 /$ j.jtcvs.2011.06.025
}

clamps and the proximal anastomosis was performed with a 22-mm Vascutek branched graft (Terumo Corporation, Tokyo, Japan) in an end-to-end fashion, after which another distal aortic clamp was applied just above the inferior mesenteric artery. The aneurysm was opened longitudinally, and back bleeding was well observed from the celiac artery. The celiac, superior mesenteric, and bilateral renal arteries were immediately cannulated and perfused. Celiac artery blood flow was maintained at $600 \mathrm{~mL} / \mathrm{min}$. This flow rate was calculated before $\mathrm{CPB}$ using duplex scanning (velocity-time integral $\times$ cross-sectional area $\times$ heart rate). The superior mesenteric and bilateral renal arteries were also pumped individually. The lower body flow rate was maintained at 1.0 to $1.5 \mathrm{~L} / \mathrm{min}$. All of the intercostal and lumbar arteries were sacrificed. Each visceral branch was separately reconstructed and the proximal aorta was declamped. The inferior mesenteric artery was sacrificed. A Vascutek bifurcated graft was used for reconstruction of the bilateral common iliac arteries and then graft-tograft anastomosis was performed. No cardiac ischemia was observed with intraoperative electrocardiography or transesophageal echocardiography. Postoperative computed tomography demonstrated patency of the GEA graft (Figure 1).

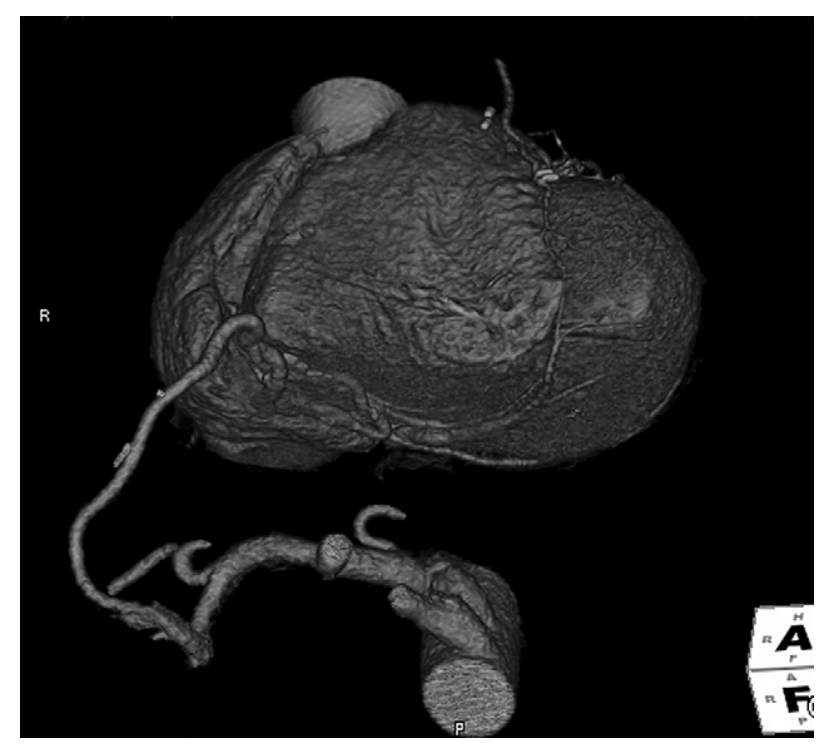

FIGURE 1. Computed tomography showing patency of visceral arteries with gastroepiploic and radial artery grafts after the thoracoabdominal aortic aneurysm repair. 


\section{DISCUSSION}

To the best of our knowledge, this is the first case report of a TAAA repair in a patient with a GEA graft for coronary artery revascularization. The GEA has been widely used as a graft for $\mathrm{CABG}$, especially for right coronary artery revascularization. In this case, the GEA and radial artery were used in a composite Y-graft to revascularize the right and left coronary arteries. The TAAA was not identified at the time of CABG. We suggest that both the ascending aorta and TAAA should be screened for atherosclerosis or aneurysmal change, via computed tomography, before the GEA is used for CABG. If TAAA is detected by preoperative computed tomography, separate or combined operations can be considered. Recently, Attaran and associates ${ }^{2}$ reported 2 successful cases of combined TAAA repair and $\mathrm{CABG}$.

In this case, we used partial CPB for TAAA repair. Celiac artery flow rate was determined before CPB using duplex scanning. Close monitoring for cardiac ischemia was performed using electrocardiography and transesophageal echocardiography. Hypothermic circulatory arrest can also be considered for TAAA repair, ${ }^{3-5}$ which has the advantage of making sequential aortic clamping and separate perfusion of the visceral arteries unnecessary. This may be a feasible alternative for cases such as the one presented for surgeons who routinely use hypothermic circulatory arrest.

In conclusion, TAAA repair can be safely performed in a patient with a patent GEA graft used for CABG using partial CPB. Duplex scanning was useful to determine celiac artery flow rate in this case.

\section{References}

1. Suzuki T, Asai T, Matsubayashi K, Kambara A, Kinoshita T, Takashima N, et al. In off-pump surgery, skeletonized gastroepiploic artery is superior to saphenous vein in patients with bilateral internal thoracic arterial grafts. Ann Thorac Surg. 2011; 91:1159-64.

2. Attaran S, Field M, Kuduvalli M, Oo A. A combined procedure of thoracoabdominal aortic aneurysm repair and coronary artery bypass grafting: report of two cases. J Thorac Cardiovasc Surg. 2011;141:1078-9.

3. Kulik A, Castner CF, Kouchoukos NT. Outcomes after thoracoabdominal aortic aneurysm repair with hypothermic circulatory arrest. $J$ Thorac Cardiovasc Surg. 2011;141:953-60.

4. Fehrenbacher JW, Siderys H, Terry C, Kuhn J, Corvera JS. Early and late results of descending thoracic and thoracoabdominal aortic aneurysm open repair with deep hypothermia and circulatory arrest. J Thorac Cardiovasc Surg. 2010;140: S154-60.

5. Kouchoukos NT, Masetti P, Rokkas CK, Murphy SF. Hypothermic cardiopulmonary bypass and circulatory arrest for operations on the descending thoracic and thoracoabdominal aorta. Ann Thorac Surg. 2002;74:S1885-7.

\title{
A new type of aortic arch interruption without significant patent ductus arteriosus and with no ventricular septal defect
}

\author{
Alexandre Cazavet, MD, Pierre-Emmanuel Seguela, MD, Philippe Acar, MD, PhD, and \\ Bertrand Leobon, MD, PhD, Toulouse, France
}

We report the case of an infant with a previously unrecorded type of aortic arch interruption (AAI). There was only insignificant patent ductus arteriosus and no ventricular septal defect. Although this congenital heart condition did not fall within the type B1 classification, it may have had the same underlying genetic cause.

\footnotetext{
From the Department of Pediatric Cardiology and Pediatric Cardiovascular Surgery, University Children Hospital of Purpan, Toulouse, France.

Disclosures: Authors have nothing to disclose with regard to commercial support.

Received for publication June 11, 2011; accepted for publication June 28, 2011; available ahead of print July 28, 2011.

Address for reprints: Bertrand Leobon, MD, PhD, Department of Pediatric Cardiology \& Pediatric Cardiovascular Surgery, University Children Hospital of Purpan, 330, Avenue de Grande Bretagne, TSA 70034, 31059 Toulouse Cedex 9, France (E-mail: leobon.b@chu-toulouse.fr).

J Thorac Cardiovasc Surg 2012;143:237-9

$0022-5223 / \$ 36.00$

Copyright (c) 2012 by The American Association for Thoracic Surgery doi:10.1016/j.jtcvs.2011.06.031
}

\section{CLINICAL SUMMARY}

A 2.5-month-old girl was referred to our hospital for collapses and cardiac murmur. She had normal height and weight development, and physical examination revealed only a low systolic murmur.

Two-dimensional echocardiography showed an AAI with a small patent ductus arteriosus of $2 \mathrm{~mm}$, no ventricular septal defect, and an atrial septal defect of $4 \mathrm{~mm}$. It also showed a left ventricular hypertrophy but without left ventricular outflow tract obstruction. Electroencephalography and brain magnetic resonance imaging (with a complete Willis circle) were normal. Both 2- and 3-dimensional computed tomographic scan angiography (Figure 1, $A, B$, and $C$ ) established the diagnosis. The ascending aorta gave rise to both carotid arteries, and the descending aorta was supplied by large subclavian arteries supplemented by collaterals between external carotids and vertebral arteries. The right subclavian artery was retroesophageal; however, bronchoscopy and esophageal opacification showed no significant 